Diyala Journal

ISSN 1999-8716

of Engineering

Printed in Iraq

Sciences

Vol. 06, No. 03, pp. 28-39, September 2013

\title{
DESIGN OF FINITE IMPULSE RESPONSE FILTERS BASED ON GENETIC ALGORITHM
}

\author{
Raaed Faleh Hassan ${ }^{1}$, Ali Subhi Abbood ${ }^{2}$ \\ ${ }^{1,2}$ College of Elec. \& Electronic Techniques, Foundation of Technical Education Baghdad \\ E-mail: drraaed@coleetech.net ${ }^{1}$, engineer_alisubhi@yahoo.com ${ }^{2}$ \\ (Received: 11/3/2012; Accepted:5/11/2012)
}

\begin{abstract}
Genetic Algorithms (GAs) are used to solve many optimization problems in science and engineering such as pattern recognition, robotics, biology, medicine, and many other applications. The aim of this paper is to describe a method of designing Finite Impulse Response (FIR) filter using Genetic Algorithm (GA). In this paper، the Genetic Algorithm not only used for searching the optimal coefficients, but also it is used to find the minimum number of Taps، and hence minimize the number of multipliers and adders that can be used in the design of the FIR filter. The Evolutionary Programming is the best search procedure and most powerful than Linear Programming in providing the optimal solution that is desired to minimize the ripple content in both passband and stopband. The algorithm generates a population of genomes that represents the filter coefficient and the number of taps, where new genomes are generated by crossover and mutation operations methods. Our proposed genetic technique has able to give better result compare to other method.

The FIR filter design using Genetic Algorithm is simulated using MATLAB programming language version 7.6.0.324 (R2008a).

Keywords: Genetic Algorithm Optimization, Finite Impulse Response filter design, Signal Processing.
\end{abstract}

\section{1- INTRODUCTION}

The conventional approach to filter design is to select one of the standard polynomial transfer functions that satisfies the response specifications, followed by the implementation of the transfer function in one of the standard circuit structures. In many cases this approach is inadequate and an optimization is required ${ }^{(1)}$. Genetic algorithm optimization methods have 
emerged as a powerful approach to solving the more difficult optimization problems ${ }^{(2)}$. Genetic Algorithms (GAs) represent a learning or adaptation method that is analogous to biological evolution according to Darwin's theory of evolution (Darwin 1859) and can be described as a kind of simulated evolution ${ }^{(3)}$. GAs are often used to solve complex optimization problems that are either very difficult or completely impractical to solve using other methods ${ }^{(4)}$.

For the related works, in ${ }^{(2)}$, the orthogonal GA (OGA), based on the so-called experimental design technique has been used to obtain fixed point implementations of linearphase FIR filters, in ${ }^{(5)}$, the GA has been used to design a minimum phase and stable digital filters for FIR and IIR filters, in ${ }^{(6)}$, the design method for minimum phase digital FIR filters using GA has been presented, and in ${ }^{(7)}$, the genetic algorithm (GA) has been used to design a multiplier-less FIR digital filters consisting of a cascade of primitive linear phase sections, note that in all these works, the Genetic Algorithm (GA) is used to find the optimal coefficient values to a predefined number of taps. In this work the Genetic Algorithm (GA) is used to find the minimum number of taps and the values of the optimal coefficients that represent an estimate to the ideal filter simultaneously.

Digital FIR filters have several design and implementation advantages, the phase response can be exactly linear, they are relatively easy to design since there are no stability problems, they are efficient to implement, and the DFT can be used in their implementation ${ }^{(8)}$.

The paper organization is as follows: Section 2 presents theoretical background of digital FIR filter. Section 3 gives an introduction to the Genetic Algorithms and their advantages compared with other methods. Section 4 illustrates the proposed FIR filter design method for the design of Lowpass FIR filter and Section 5 shows the simulation results to the design of FIR filters using genetic algorithm optimization and compare these results with the results obtained using Least Square (LS) and Equiripple optimization methods. Finally, Section 6 presents a conclusion from this work.

\section{2- DIGITAL FIR FILTER}

An FIR filter of length $M$ with input $x(n)$ and output $y(n)$ is described by the difference equation ${ }^{(9)}$ :

$$
\begin{gathered}
y(n)=\sum_{k=0}^{M-1} b_{k} x(n-k) \\
=b_{0} x(n)+b_{1} x(n-1)+\ldots \ldots+b_{N} x(n-M+1)
\end{gathered}
$$


where $\left(b_{k}\right)$ is the set of filter coefficients. Alternatively, we can express the output sequence as the convolution of the unit sample response $h(n)$ of the system with the input signal. Thus (9):

$$
y(n)=\sum_{k=0}^{M-1} h(k) x(n-k)
$$

Where the lower and upper limits on the convolution sum reflect the causality and finiteduration characteristics of the filter. Clearly, (1) and (2) are identical in form and hence it follows that $b_{k}=h(k), k=0,1,2 \ldots M-1$.

The filter can also be characterized by its system function ${ }^{(9)}$ :

$$
H(z)=\sum_{k=0}^{M-1} h(k) z^{-k}
$$

The roots of this polynomial constitute the zeros of the filter.

An FIR filter is linear-phase if (and only if) its coefficients are symmetrical around the center coefficient $^{(10)}$. And its unit sample response satisfies the condition ${ }^{(9)}$ :

$$
h(n)=h(M-1-n) \quad n=0,1,2, \ldots, M-1
$$

when the symmetry condition is incorporated into, we have $\mathrm{e}^{(9)}$ :

$$
\begin{gathered}
H(z)=h(0)+h(1) z^{-1}+\cdots+h(M-2) z^{-(M-2)}+h(M-1) z^{-(M-1)} \\
=z^{-(M-1) / 2}\left\{h\left[\frac{M-1}{2}\right]+\sum_{n=0}^{\frac{M-3}{2}} h(n)\left[z^{\frac{(M-1-2 k)}{2}} \pm z^{-\frac{(M-1-2 k)}{2}}\right]\right\} \\
\left.=z^{-\frac{M-1}{2}} \sum_{n=0}^{\left(\frac{M}{2}\right)-2} h(n)\left[z^{\frac{(M-1-2 k)}{2}} \pm z^{-\frac{(M-1-2 k)}{2}}\right]\right\}
\end{gathered}
$$

When $h(n)=h(M-1-n), H(\omega)$ can be expressed as ${ }^{(9)}$ :

$$
H(\omega)=H r(\omega) e^{-\frac{j \omega(m-1)}{2}}
$$

Where $H_{r}(\omega)$ is a real function of $\omega$ and can be expressed as ${ }^{(9)}$ :

$$
\begin{array}{ll}
H_{r}(\omega)=h\left(\frac{M-1}{2}\right)+2 \sum_{n=0}^{\left(\frac{M-3}{2}\right)} h(n) \cos \omega\left(\frac{M-1}{2}-n\right) & \text { M odd } \\
H_{r}(\omega)=2 \sum_{n=0}^{\left(\frac{M}{2}\right)-1} h(n) \cos \omega\left(\frac{M-1}{2}-n\right) & \text { M even }
\end{array}
$$

The phase characteristic of the filter for both $M$ odd and $M$ even is ${ }^{(9)}$ : 


$$
\theta(\omega)= \begin{cases}-\omega\left(\frac{M-1}{2}\right), & \text { if } \operatorname{Hr}(\omega)>0 \\ -\omega\left(\frac{M-1}{2}\right)+\pi, & \text { if } \operatorname{Hr}(\omega)<0\end{cases}
$$

We note that, for a symmetric $h(n)$, the number of filter coefficients that specify the frequency response is $(M+1) / 2$ when $M$ is odd or $M / 2$ when $M$ is even.

Linear phase FIR filters have several advantages, design problem contains only real arithmetic and not complex arithmetic, linear phase filters provide no delay distortion and only a fixed amount of delay, and the filter of length $M$, the number of operations are of the order of $M / 2^{(8)}$.

In summary, the problem of FIR filter design is simply to determine the $\mathrm{M}$ coefficients $h(n), n=0,1,2, \ldots, M-1$, from a specification of the desired frequency response $H_{d}(w)$ of the FIR filter ${ }^{(9)}$. Figure (1) represent a direct form structure implementation of an FIR filter with symmetric coefficients ${ }^{(11)}$.

\section{3- GENETIC ALGORITHM}

The GA is an artificial genetic system based on the processes of natural selection and reproduction found in biological systems ${ }^{(7)}$. Because of their power and ease of implementation, genetic algorithms have been widely applied to combinatorial optimization problems, i.e., problems where complexity increases exponentially with the problem dimensions ${ }^{(12)}$. Genetic algorithms can find optimal solutions among the search space with the operators like crossover and mutation ${ }^{(13)}$. GAs has several advantages over traditional search and optimization algorithms. These advantages stem in part from its ability to maintain simultaneously information about variety of points in the solution space. This helps prevent the GA from being trapped at inferior local minima. Another feature of GAs is their use of building blocks in creating new solutions. This allows a GA to take advantage of the high quality sub-solutions ${ }^{(14)}$. GA is an example of mathematical technology transfer: by simulating evolution one can solve optimization problems from a variety of sources. Today, GAs are used to resolve complicated optimization problems $(15,16$, and 17). The genetic algorithm loops over an iteration process to make the population evolve. Each iteration consists of the following steps ${ }^{(17)}$ :

\section{a) Initialization}


The algorithm begins by creating a random initial population. For example, the initial population consists 20 individuals, which is the default value of population size in the population option.

b) Evaluation

At the beginning of each generation of the algorithm, the fitness of each particle must be calculated.

c) Selection

The algorithm selects individuals for reproduction. This selection is done randomly with probability depending on the relative fitness of the individual as a parent.

\section{d) Mating}

Mating is the creation of one or more offspring from the parents selected in the pairing process. The genetic makeup of the population is limited by the current population.

\section{e) Mutation}

By applying random changes to a single individual in the current generation to create a child.

\section{f) Replacement}

During the last step, individuals from the old population are killed and replaced by the new ones.

A typical GA cycle is shown in figure (2) ${ }^{(18)}$. While figure (3) illustrates the canonical genetic algorithm $^{(19)}$.

\section{4- DESIGN METHOD OF LOW PASS FIR FILTER USING GA}

Consider a linear phase FIR filter, we want to find an $N$ tap FIR filter that will approximate the frequency response of the ideal Lowpass filter as shown in figure (4).

The transfer function of an FIR filter of order $\mathrm{N}$ is:

$$
H(z)=\sum_{n=0}^{N} h(n) z^{-n}
$$

The corresponding frequency response is given by:

$$
H\left(e^{j w}\right)=\sum_{n=0}^{N} h(n) e^{-j n \omega}
$$

In the case of linear phase, the transfer function will have symmetric coefficients that is $h(n)$ $=h(-n)$ and :

$$
H\left(e^{j \omega}\right)=H(w) e^{j \phi(\omega)}
$$

where 


$$
H(\omega)=h\left[\frac{N}{2}\right]+\sum_{n=1}^{N / 2}\left(h\left[\frac{N}{2}-n\right][2 \cos (n \omega)]\right)
$$

Now we sample the frequency in $[0, p i]$ with $N$ points,

$$
H d(\omega)=\left[H d\left(\omega_{1}\right), H d\left(\omega_{2}\right), \ldots \ldots, H d(\omega N)\right]^{T}
$$

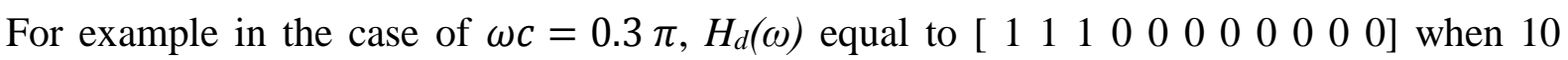
samples between 0 and pi are tacked.

$$
H(\omega)=\left[H\left(\omega_{1}\right), H\left(\omega_{2}\right), \ldots \ldots, H(\omega N)\right]^{T}
$$

The error function $(\varepsilon)$ now can be defined as:

$$
\varepsilon(\omega)=[H d(\omega)-H(\omega)]
$$

And the fitness function that has been used is the inverse of the absolute value of the error function $\mathcal{E}(H)$ :

$$
\text { fitness }=\frac{1}{a b s(\varepsilon(\omega))}
$$

Where the matrix of the filter coefficients is:

$$
h=h\left[\frac{N-1}{2}\right], h\left[\frac{N-1}{2}+1\right], \ldots \ldots \ldots \ldots[N-1]
$$

Now the Genetic Algorithm used to find the impulse response, and the matrix that will be input to the GA will be as follow:

$$
x=\left[M, h\left[\frac{N-1}{2}\right], h\left[\frac{N-1}{2}+1\right], \ldots \ldots h[N-1]\right]
$$

where

$$
M=\frac{N-1}{2}
$$

\section{5- RESULTS AND COMPARISON}

The proposed algorithm of Genetic optimization was applied to the design of a symmetric linear phase Low pass FIR filter with a $0.3 \pi$ cutoff frequency and the results obtained are compared with the results from using a least-squares error and equiripple minimization methods of designing symmetric FIR filter. The control parameters of the GA used in this work are as the following:-

- Generation Number: 1000.

- Population Size: 2000.

- $\quad$ Fitness function $=\frac{1}{\boldsymbol{a b s}(\mathcal{E}(\omega))}$

- Population type: Double Vector.

- Selection function: Stochastic uniform. 
- Mutation function: Gaussian.

- Crossover function: Scattered.

The simulation results obtained by using GA when absolute error function is used in passband and stopband transition regions compared with the least-squares error and equiripple minimization methods are given in Figures (5 and 6). From figure (5), the number of taps obtained after running the Genetic Algorithm search method for the design of symmetric linear phase Low pass FIR filter is (11) and the impulse response coefficients are presented in Table (1). Figure (6) represent the Magnitude Response of symmetric linear phase Low pass GA FIR filter compared with the symmetric linear phase Low pass leastsquares error and Equiripple FIR filters respectively.

\section{6- CONCLUSIONS}

With problems that are not convex, have several local minima, the GA offers the advantages of global optimization in addition the GA does that in a fraction of the number of evaluations required to obtain the solution. By contrast, classical optimization algorithms though very efficient, they are not equipped to discard inferior local solutions in favor of more optimal ones. In this paper, GA has been applied to the design of linear phase Lowpass FIR filters. Simulation results for the filter design using GA were compared with corresponding results achieved with a design based on a Least-Squares (LS) and Equiripple methods. As seen from the simulation results obtained after applying the GA in the design of low pass FIR filter, the proposed method is able to design linear phase filters, improved design have been achieved relative to designs produced by well-known state of the-art techniques for two reasons, first the filter that was designed using GA give us the exact cutoff frequency, second, the ripples in the pass band and in the stop band regions are attenuated successfully. The Genetic Algorithm is used as a search method to find the minimum number of taps and the optimum coefficients. Used as a tool for global optimization, the GA performs faster, better and more thoroughly.

\section{REFERENCES}

1. Deng, B., (2001), "Discretization-free design of variable fractional delay FIR filters", IEEE Trans (Circuits Syst. 11): Analog and Digital Signal Processing, Vol. 48, No. 6, pp. 637- 644. 
2. Ahmad, Sabbir U. and Andreas Antoniou, (2006), "Cascade-Form Multiplierless FIR Filter Design Using Orthogonal Genetic Algorithm”, IEEE International Symposium on Signal Processing and Information Technology, pp. 932-937.

3. Zaknich, A., (2005), "Principles of Adaptive Filters and Self-learning Systems", Springer-Verlag London Limited.

4. Arslan ,T., and D.H. Horrocks, (1995), “The Design of Analogue and Digital Filters using Genetic Algorithms", the Institution of Electrical Engineers (IEE), pp. 2-5.

5. Karaboga, Nurhan and Bahadir Cetinkaya, (2004), "Performance comparison of Genetic Algorithm based design methods of digital filters with optimal magnitude response and minimum phase”, IEEE. PP. 644-647.

6. Karaboga, Nurhan and Bahadir Cetinkaya, (2004), "Optimal design of minimum phase digital FIR filters by using Genetic Algorithm”, IEEE. PP. 24-28.

7. Wade, G., A. Roberts and G. Williams, (1994), "Multiplier-less FIR filter design using a genetic algorithm”. IEE Proc.-Vis (Image Signal Process.), Vol. 141, No. 3, pp.175180.

8. lngle, Vinay K. and John G. Proakis, (1997), "DIGITAL SIGNALP ROCESSING USING MATLAB V.4", PWS Publishing Company and International Thomson Publishing Inc.

9. Proakis, John G., and Dimitris G. Manolakis, (1996), "Digital Signal Processing: Principles, Algorithms, and Applications", $3^{\text {rd }}$ Edition, Prentice-Hall, Inc.

10. Rao, Nagaraja S., M. N. Giri Prasad and Manoj Kumar Singh, (2009), "The robust design of linear phase FIR filter using mex-mutation evolutionary programming". ARPN Journal of Engineering and Applied Sciences. VOL. 4, NO. 4, pp. 102-108.

11. Rosa, Vagner S., Fábio F. Daitx, Eduardo Costa, and Sergio Bampi, (2009), "Design Flow for the Generation of Optimized FIR Filters", IEEE, p. 1000-1005.

12. Lee, A., M. Ahmadi, G.A. Jullien, W.C. Miller, and R.S. Lashkari, (1998), "Digital Filter Design Using Genetic Algorithm", IEEE, pp34-38.

13. Malhotra, Rahul, Narinder Singh \& Yaduvir Singh, (2011), "Genetic Algorithms: Concepts, Design for Optimization of Process Controllers", Canadian Center of Science and Education, Vol. 4, No. 2, PP. 39-54.

14. Gen, Mitsuo and Runwei Cheng, (2000), "Genetic Algorithms and Engineering Optimization", John Wiley \& Sons, Inc.

15. Sivanandam, S.N., and S. N. Deepa, (2008), "Introduction to Genetic Algorithms", Springer. 
16. Haupt, Randy L., and Sue Ellen Haupt, (2004), "PRACTICAL GENETIC ALGORITHMS", $2^{\text {nd }}$ EDITION, John Wiley \& Sons Inc.

17. Hammood, Dalal A., Safaa S. Omran, and Ali S. Al-khalid, (2011), "Using Genetic Algorithms in Cryptanalysis for system ciphering", Foundation of Technical Education, College of Electrical and Electronic Techniques, Iraq.

18. K. S. Tang, K. F. Man, S. kwong and Q. HE, (1996), "Genetic Algorithms and their Applications", IEEE SIGNAL PROCESSING, Vol. (), No. (), p. 22-37.

19. Affenzeller, Michael Stephan, Winkler, Stefan Wagner, and Andreas Beham, (2009), "Genetic Algorithms and Genetic Programming: Modern Concepts and Practical Applications", Taylor \& Francis Group, LLC.

Table (1): Impulse response coefficients of GA Low pass FIR filter compared with Least-

Squares (LS) and Equiripple Low pass FIR filters.

\begin{tabular}{|c|c|c|}
\hline $\begin{array}{c}\text { GA Low Pass FIR } \\
\text { Filter coefficients }\end{array}$ & $\begin{array}{c}\text { LS Low Pass FIR } \\
\text { Filter coefficients }\end{array}$ & $\begin{array}{c}\text { Equiripple Low Pass } \\
\text { FIR Filter coefficients }\end{array}$ \\
\hline 0.0204 & -0.0637 & 0.0262 \\
\hline 0.0535 & -0.0468 & 0.0544 \\
\hline 0.0917 & 0.0328 & 0.0938 \\
\hline 0.1259 & 0.1514 & 0.1336 \\
\hline 0.1504 & 0.2575 & 0.1634 \\
\hline 0.1597 & 0.3000 & 0.1745 \\
\hline 0.1504 & 0.2575 & 0.1634 \\
\hline 0.1259 & 0.1514 & 0.1336 \\
\hline 0.0917 & 0.0328 & 0.0938 \\
\hline 0.0535 & -0.0468 & 0.0544 \\
\hline 0.0204 & -0.0637 & 0.0262 \\
\hline
\end{tabular}

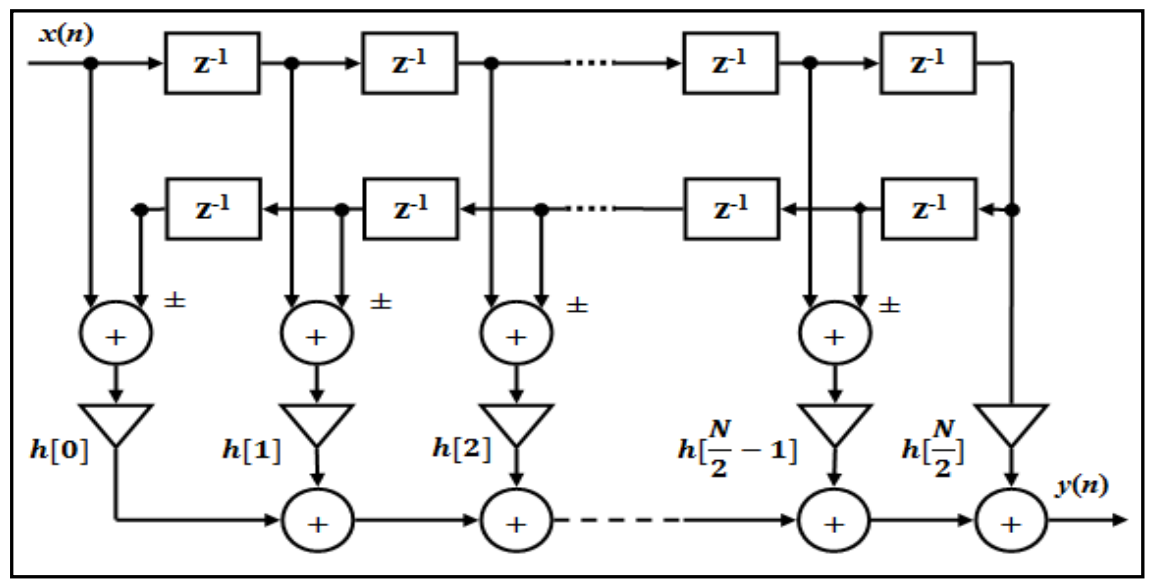

Fig. (1): A direct form FIR filter ${ }^{(11)}$. 


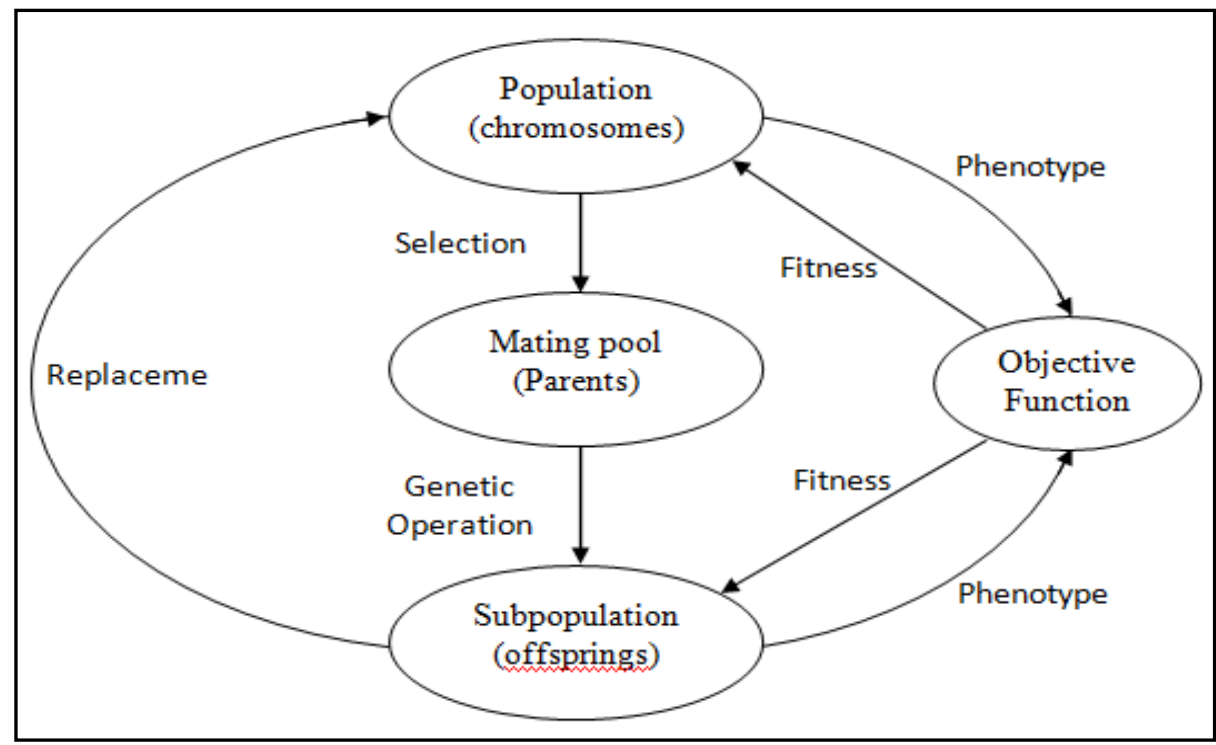

Fig. (2): GA cycle ${ }^{(18)}$.

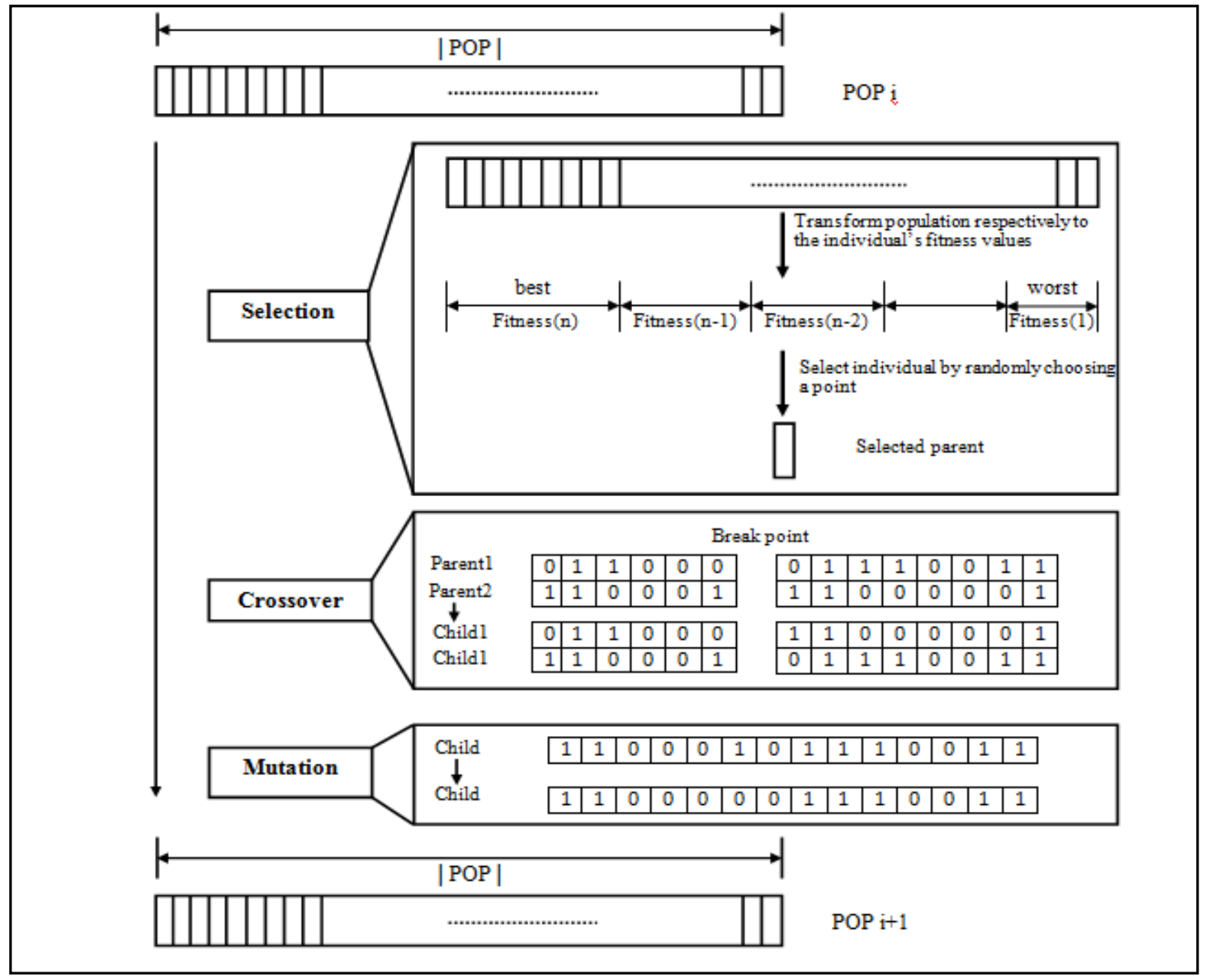

Fig. (3): The canonical genetic algorithm ${ }^{(19)}$. 


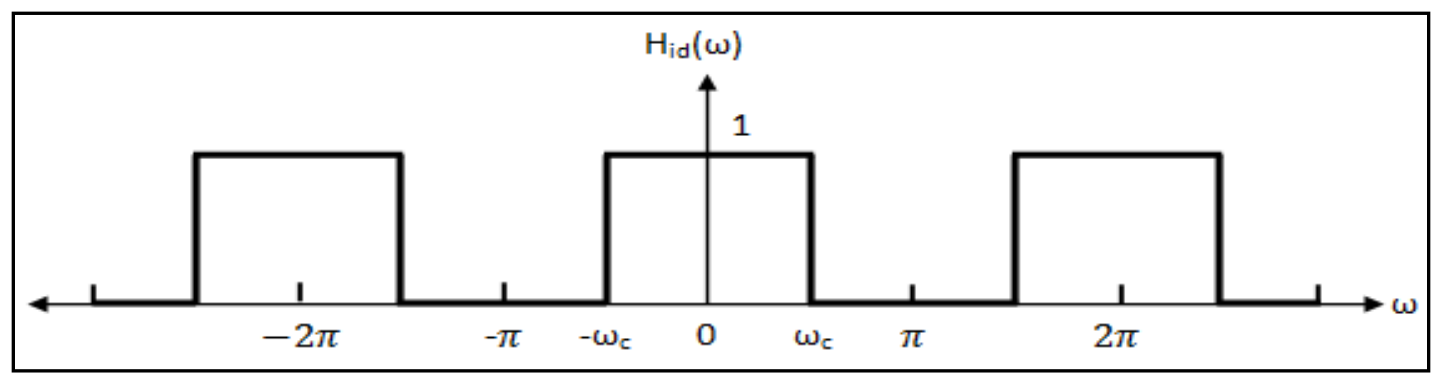

Fig. (4): Frequency response of an ideal Lowpass filter.

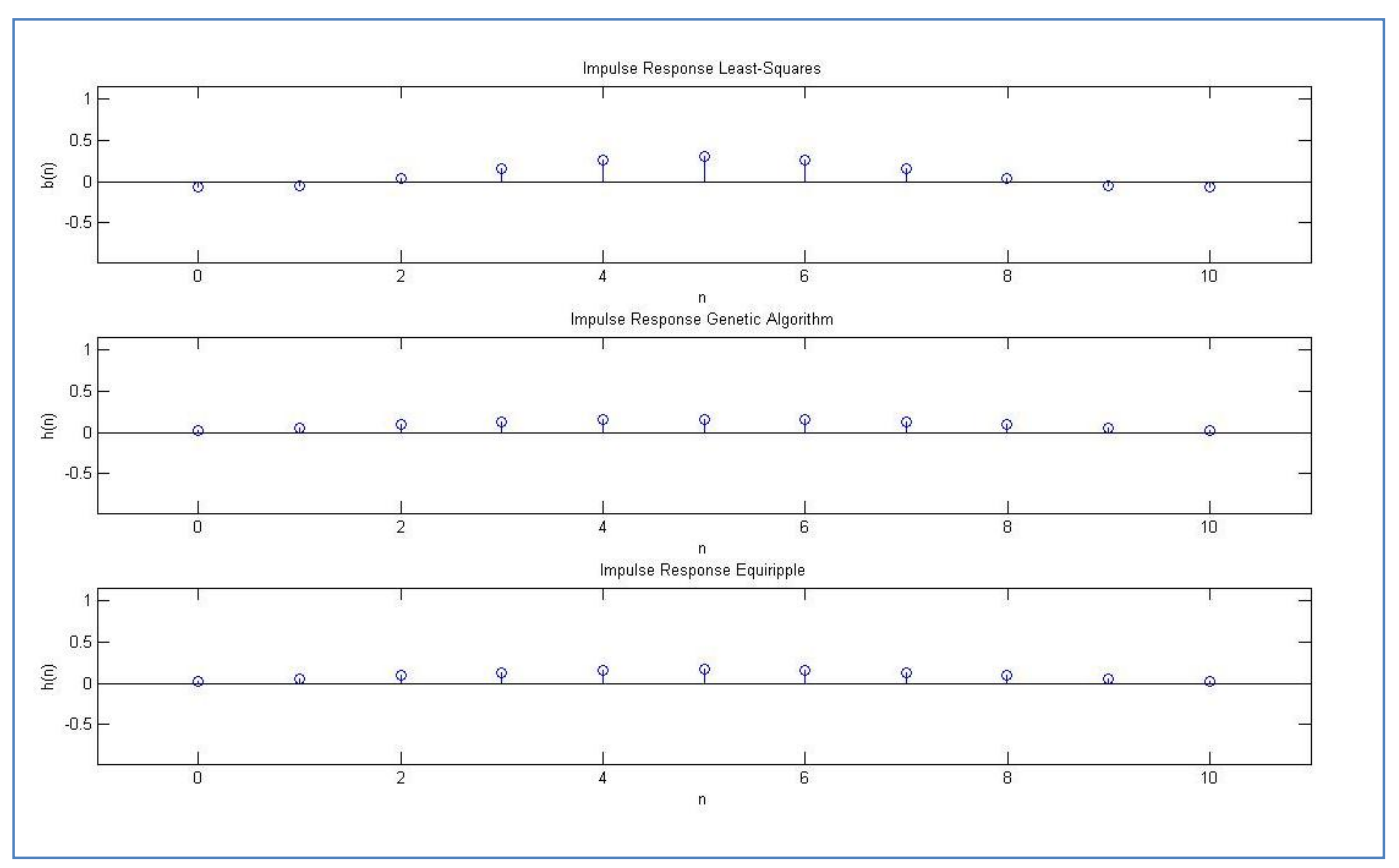

Fig. (5): The Impulse Response for the Low Pass GA FIR filter compared with the LeastSquares and Equiripple FIR filters.

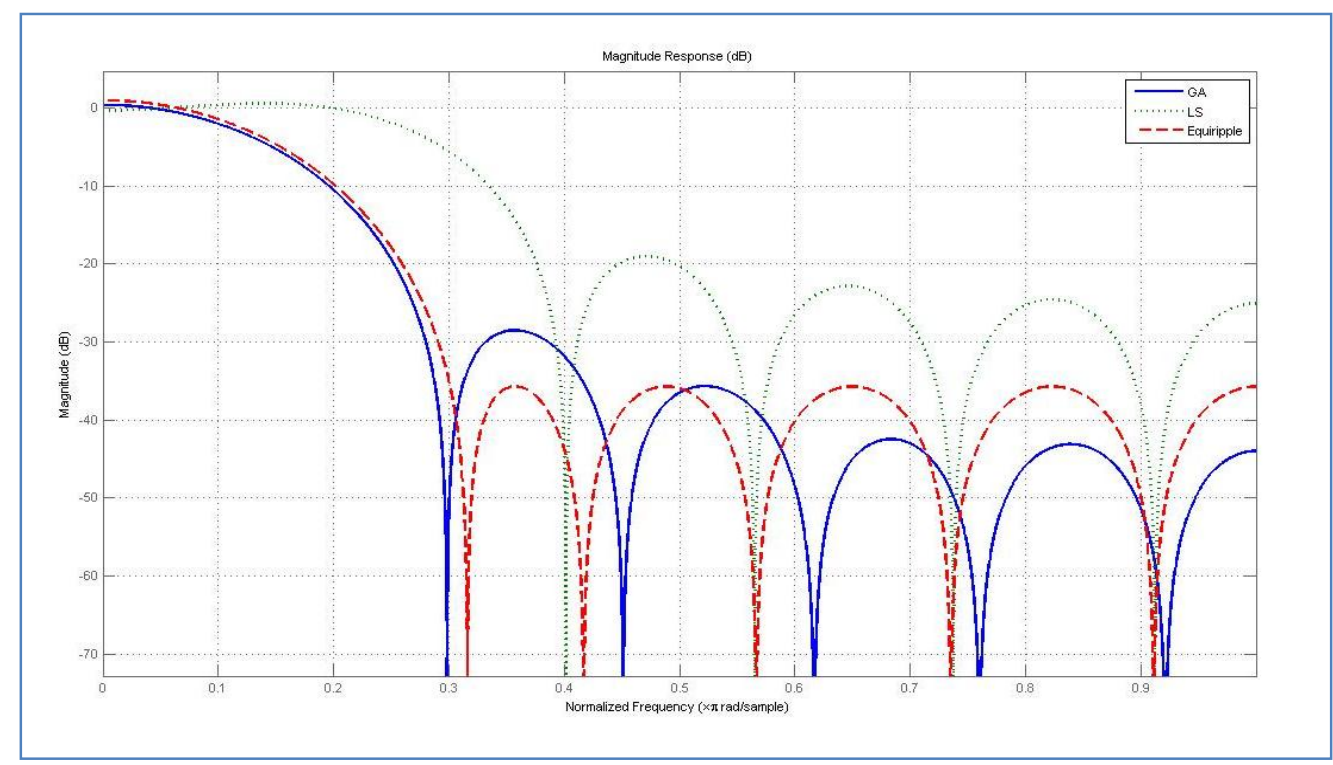

Fig. (6): Magnitude Response of Low Pass GA FIR filter compared with the Least-Squares and Equiripple FIR filters. 


\section{تصميم مرثحات ذات استجابة نبضة متناهية بالاعتماد على الخوارزميات الجينية}

$$
\begin{aligned}
& \text { علي صبحي عبود } \\
& \text { كلية التقنيات الكهربائية و الالكترونية } \\
& \text { هيئة التعليم التقني } \\
& \text { العر اق - مبنداد }
\end{aligned}
$$

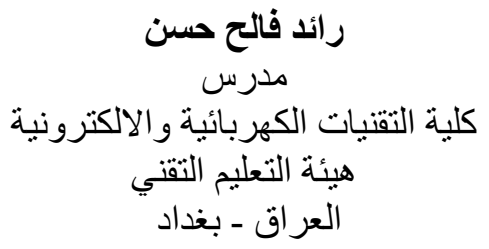

تستخدم الخوارزميات الجينية (GAs) لحل العديد من مسائل التحسين الصعبة في العلوم والهندسة مثل التعرف على

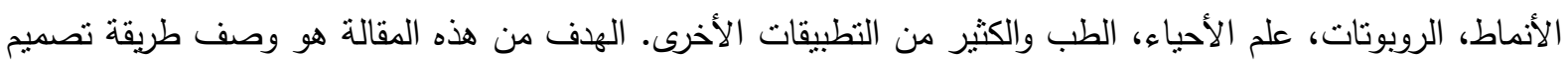

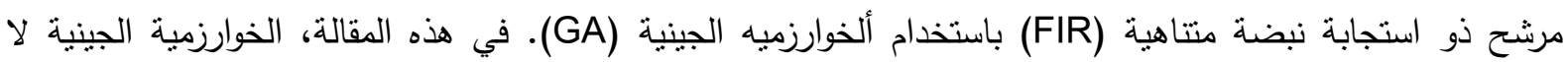

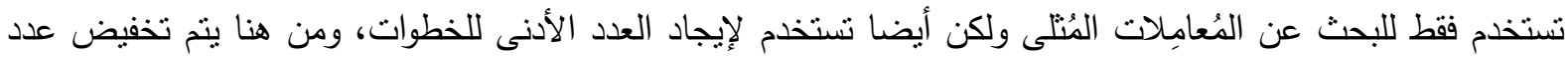

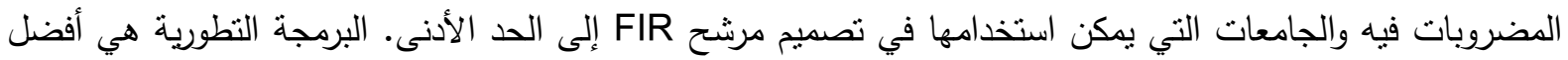

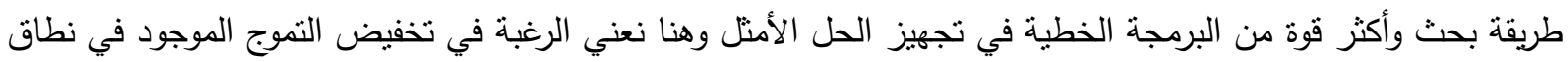

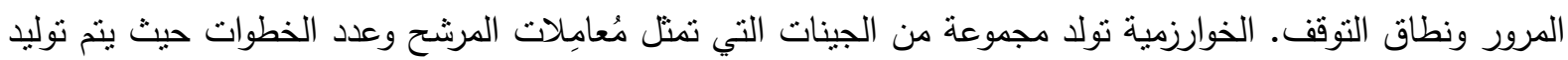
جينات جديدة بواسطة عمليات التبادل والطفرة. تقنيتا الجينية المقترحة قادرة على أن تعطي نتائج أفضل مقارنةً مع بقية

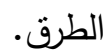

تصميم مرشح FIR باستخدام الخوارزمية الجينية تمت محاكاتها باستخدام لغة برمجة ماتلاب نسخة 7.6.0.324 الكلمات الدالة: التحسين باستخدام الخوارزميات الجينية، تصميم مرشح ذو استجابة اندفاع متتاه، معالجة الإشارة. 